Running head: Chinese-background Australian Students

\title{
Chinese-background Australian Students' Academic Self-concept, Motivational Goals, and Achievements in Math and English
}

Alexander Seeshing YEUNG, Australian Catholic University Feifei HAN, The University of Sydney

\begin{abstract}
This study reports the effects of gender, cultural backgrounds (Chinese vs. Anglo), and the interaction of the two on academic self-concepts, achievement goals, and academic achievements in math and English among 2362 Australian high school students. The results showed that Anglobackground students had higher self-concept in English than Chinese-background students, but their performance in English was in fact lower. Chinese-background students had higher mastery goal and achievements in math and English. Gender stereotype was found on math self-concept such that male students had higher self-concept than females. The interaction between gender and culture was only significant on students' mastery goal in English, showing that Chinese females had the highest mastery goal in English whereas Anglo males were the lowest. In general we observed that Chinese students were more motivated and achieved higher academically in the two subjects. But they felt less confident about their competence. In educating Chinese heritage learners, teachers need to understand Chinese culture and help students boost their competence beliefs.
\end{abstract}

Key words: Chinese-background students, gender, culture, self-concept, achievement goals, Australian high school 
Students' self-concept and motivation are widely acknowledged as two important psychological constructs, which have prominent influence on students' academic performance (Yeung, 2011; Yeung, Han, \& Lee, 2016). However, research on how gender role may affect students' academic self-concept and motivation often produces inconsistent results. What further complicates the issue is that gender often interacts with other factors, such as students' cultural backgrounds. For students from the same society but with diverse cultural backgrounds, self-concept and motivation may be affected by the cultural values formed in a particular cultural group. Hence these psychosocial constructs may vary among students from different cultures even though they are educated within the same educational system. Australia is well known for its well-blended multicultural society, in which Western cultures meet Eastern cultures. While Western cultures tend to value people's innate competence, Eastern cultures, especially Chinese culture under the influence of Confucianism, merits effort and diligence in education (Yeung \& Yeung, 2008; Yeung et al., 2016). According to Mak and Chan (1995), Chinese immigrant families in Australia, in general, retain many of their original cultural beliefs, irrespective of their socio-economic status. Whether students from a Chinese or Anglo culture in Australia differ in terms of academic self-concept, and achievement goal motivation, is the focus of the current investigation.

More specifically, the current chapter studies gender and cultural background effects on students' self-concept, achievement goal motivation, and academic achievement in the math and English, the two most important subjects for Australian high school students. Using Australian high school as the research context is meaningful because this allows us to examine whether students' cultural backgrounds rather than different educational systems influence their motivational beliefs; and whether similarities and differences between cultural groups are further affected by students' gender.

\section{Academic Self-concept and Its Impact}


Self-concept - "a person's perception of himself...formed through his experience with his environment...and influenced especially by environmental reinforcements and significant others" (Shavelson, Hubner, \& Stanton, 1976, p. 411) has been positively described as "making things happen", and "enabling human potential to its full extent" (Marsh \& Craven, 2006). Academic selfconcept, which is defined as students' self-perception and self-appraisal capabilities and enjoyment in academic domains, is a significant contributing factor to various desirable educational outcomes (Craven \& Yeung, 2015).

The structure of self-concept has been empirically demonstrated as multidimensional and domain specific (Arens, Yeung, Craven, \& Hasselhorn, 2011). Marsh (1990), for example, found distinct self-concepts in a number of school subjects, including verbal, math, physical, art, music, and religion, with a general academic self-concept as an overarching construct. Following the domain specificity principles (Arens et al., 2011; Swann, Chang-Schneider, \& Larsen McClarty, 2007), in our study, we focused on the two most important school subjects for Australian high school students: math and English.

In recent years, academic self-concept has been differentiated into cognitive and affective components, known as the competence-affect distinction (e.g., Arens et al., 2011; Pinxten, Marsh, De Fraine, Van Den Noortgate, \& Van Damme, 2014). While the competence part surveys whether students perceive themselves as being good at academic work, the affect part asks whether students consider themselves as liking schoolwork (Pinxten et al., 2014). The distinction of competence and affect is important. Confidence about one's ability in academic endeavour is likely to be associated with short-term educational outcomes, such as tests performance and academic results; whereas liking of school and enjoyment in doing school activities tend to be linked with long-term educational benefits, like academic retention and future academic aspirations (Yeung, 2011). We only considered the competence component in this study, as we only examined short-term educational outcomes - achievement scores. 
The relationship between academic self-concept and achievement is found to be reciprocal, dynamic, and mutually reinforcing each other (Marsh \& Craven, 2006). This means that students' prior positive academic self-concept is able to lead to enhanced academic performance in the subsequent year, and their previous achievement also has positive effects on their later competence beliefs in schoolwork (Möller, Retelsdorf, Köller, \& Marsh, 2011). Numerous researchers have emphasized the importance of nurturing students' self-beliefs of competence in academic work, because a high self-perception of competence is often found to be a stronger predictor of performance than students' actual ability in specific tasks (Pajares \& Schunk, 2002).

\section{Achievement Goals and Their Impact}

In the last couple of decades, motivation research has advanced enormously and a number of theories have been generated. Among these different perspectives, achievement goal theory has remained popular in educational psychology (Hulleman, Schrager, Bodmann, \& Harackiewicz, 2010). Achievement goal theory was established in order to understand "students" adaptive and maladaptive responses to achievement challenges" (Senko, Hulleman, \& Harackiewicz, 2011, p. 27). The goals are referred to as cognitive representations of students' purposes in different achievement scenarios (Pintrich, 2000). The goals set by students can provide them with meaningful learning purposes and help them understand learning situations (Seifert, 2004).

Among different types of goals held by students, two primary goals have been the focus of research, namely mastery and performance goals (Wolters, 2004). A mastery goal is defined as “desire to learn, improve, and develop competence" (Urdan \& Mestas, 2006, p. 354). Students who hold a mastery goal orientation are said to pay attention to the process of acquiring and developing their capabilities, mastering and completing the tasks, improving their competence over time, and self-developing in relation to self-referenced criteria. On the contrary, students who pursue a performance goal predominantly focus on demonstrating and comparing their competence through social comparison processes and obtaining positive evaluations (Elliot, 2005; King, Ganotice, \& 
Watkins, 2012). The two goals are not two dichotomous aspects of learning motivation; they can exist simultaneously within an individual (Daniels et al., 2008). While a student may focus on learning, at the same time, he or she may also be competition conscious (Pintrich, 2000).

In terms of whether the achievement goals should be conceptualized as domain-general or domain-specific, there is no conclusive evidence (Magson, Craven, Nelson, Yeung, BodkinAndrews, \& McInerney, 2014; Paulick, Watermann, \& Nückles, 2013). In this study, we used domain-specific measures of achievement goals for two reasons. First, domain-specific achievement goals would be consistent with domain specificity of self-concept used in the study. Second, as we measured math and English achievement separately, matching the achievement goals in math and English to the respective academic achievements would yield more useful information for practical applications.

\section{Gender Issues}

Research has revealed that there may be a gender stereotype on academic self-beliefs, motivation, and achievement (Meece, Glienke, \& Burg, 2006; Yeung, Craven, \& Kaur, 2012). Although boys and girls may have similar levels of self-beliefs and academic motivation at the start, gender differences tend to become observable from early elementary school and the gap will continue in high schools (Usher \& Pajares, 2008). Past self-concept research which focused primarily on competence perceptions has indicated that, in general, boys tend to have higher competence beliefs than girls (Midgley, Kaplan, \& Middleton, 2001), as boys are more likely to overestimate their competence; whereas girls tend to underestimate their abilities (Metalidou \& Vlachou, 2007). Furthermore, male and female students may have different competence beliefs in different curriculum areas. Research has consistently reported that male students tend to have higher perceptions of competence in math, science-related subjects, and sports and exercises (Klapp Leldholm \& Cliffordson, 2009), whereas female students tend to have higher self-concepts in 
language and verbal-related subjects, as well as music (Kurtz-Coastes, Rowley, Harris-Britt, \& Woods, 2008).

The gender role effect has also been reported in some motivational constructs. Midgley et al. (2001) found that girls tended to have a higher level of mastery goal than boys. Adopting a domain[u1]: On first mention, say it full. specific approach to motivation, Trautwein and Lüdtke (2009) showed that male students were more motivated and more compliant in some specific school subjects, such as math and physics, whereas their female peers tended to display avoidance or withdrawal in these subjects. These results suggest that similar to self-concept, gender may also play a role in achievement goals relevant to curriculum areas.

\section{Cultural Issues}

Cultural backgrounds may exert influences on students' academic self-beliefs and motivation (Yeung et al., 2012; 2016). This is because students from different cultural backgrounds hold specific values that are consistent with those within the societies they come from (Luo, Hogan, Yeung, Sheng, \& Aye, 2014). They may therefore have different understandings of the goals of learning and processes of learning, which in turn may shape the beliefs and motivation they hold for learning (Dekker \& Fischer, 2008). Under the influence of cultures, people in the Western and nonWestern societies have different educational theories towards learning (Yeung \& Yeung, 2008; Yeung et al., 2016). Li (2002) maintained that "heart and mind for wanting to learn" is a typical thought among people in some Eastern cultures, such as Chinese. She found that Chinese students set up knowledge seeking as a long-term goal to pursue from early years. Thus, Chinese students perceive learning process as a way to add meaning to their lives and to gain positive self-perceptions through acquiring knowledge. In her study, Li reported that Chinese students had more positive beliefs than their American peers, whereas American students placed an emphasis on learning style and intelligence. Other studies also highlighted differences in terms of self-beliefs in education between Western and Eastern cultures. While Western tradition merits students' innate competence, 
Chinese culture has a long historical tradition of valuing nurtured characteristics through hardwork and effort, which is inherited from Confucius' thoughts dated back around 500 BC (Hau \& Salili, 1991; Yeung et al., 2016). These findings all point to the emphasis of a mastery goal in Chinese learners.

\section{Interaction between Gender and Culture}

The interaction between gender and culture was also found for self-concept and academic performance (e.g., Chiu \& Klassen, 2010; Dai, 2001, Lai, 2010). For instance, Dai (2001) observed a reversed pattern in terms of gender differences on competence beliefs. For gifted American and European adolescents, males self-rated higher on general academic self-concept than females. In contrast, among gifted Chinese students, it was female students who self-perceived being more capable. Chiu and Klassen (2010) found that for students from wealthier countries and from a culture which tolerates more uncertainty, math self-concept had a stronger relationship with math achievement among boys than girls. Lai (2010) showed that Chinese girls performed better than boys in both primary and secondary schools, but for American students, this pattern was not consistent. American girls achieved better than boys in elementary school, but boys gradually caught up in math and science subjects in middle school.

\section{The Present Investigation}

The present study examines gender and cultural effects on self-concepts, two most important achievement goals (i.e., mastery and performance goals), as well as academic achievements in math and English among Australian high school students who are from a Chinese background and an Anglo background by adopting a multiple-indicator-multiple-indicator-cause (MIMIC) approach to structural equation modeling (SEM). Three research questions the study explored are:

(1) What is the effect of gender on Australian high school students' academic self-concepts, achievement goals, and academic performance in math and English? 
(2) What is the effect of culture on Australian high school students' academic self-concepts, achievement goals, and academic performance in math and English?

(3) What is the effect of gender and culture interaction on Australian high school students' academic self-concepts, achievement goals, and academic performance in math and English?

\section{Method}

\section{Research methodology}

Commented [u3]: Please describe here what research methodology you used and why.

Commented [A4]: This has been added.

The research methodology we used is quantitative through a structural equation modeling (SEM) approach, which allows simultaneous analysis of all the variables in one model and controls for measurement error so that errors are not aggregated in a residual error term (Nachtigall,

Kroehne, Funke, \& Steyer, 2003). This is deemed suitable as it enables us to examine gender, culture, and their interaction on self-concepts and achievement goals in a single model.

\section{Participants}

The study was conducted in eight high schools in Sydney, New South Wales, Australia. Altogether 2,362 students participated (males: 1,110, 47\%; females: 1,250, 52.9\%; two missing gender information). The students were in grades7-10 with ages ranging from 11 to 17 years $(M==$ $13.71, S D=1.16$ ). In this study, cultural background was operationalized as Chinese-background learners and Anglo-background learners. The Chinese category learners reported mainly speaking Chinese (Mandarin or Cantonese) at home. This sample of students included 461 Chinese learners (19.5\%). The remaining 1901 students $(90.5 \%)$ were Anglo students who reported mainly speaking English at home.

\section{Materials}

The materials used for data collection was a questionnaire and the achievement test scores in math and English. The survey started with a section on demographic information including sex, age, grade, and cultural backgrounds. The main survey had two parts: one was on students' academic self-concepts in the math and English and the other was on achievement goals in the two subjects.

Commented [GL5]: Is this too young for $7^{\text {th }}$ grade or in high school?

Commented [A6]: We doubled checked this, that was correct.
Commented [GL7]: Do you have some data on their immigration status, i.e., Australian born or foreign born, which may shed more light on the "culture" effect on English language selfperception

Commented [A8]: We operationalized Chinese background as the participants' self-reported main language at home rather than their birth place. This was because some of the participants may be the second generation of immigrants. This means that even if they the second generation of immigrants. This means that even if were born in Australia, their parents are Chinese and their
educational and cultural values may be largely Chinese-oriented. Thus, we think this is better than using birth place. 
Academic self-concepts. To measure students' academic self-concepts in math and English, Marsh's (1990) Academic Self Description Questionnaire II was adapted, as this questionnaire is the most widely used instrument for measuring academic self-concept of students from diverse cultures (Worrell, Watkins, \& Hall, 2008). There were six items for each subject, and all of them reflected an individual's perception of competence in the subjects. The items were scored on a 6-point Likert scale with 1 indicating "strongly disagree" and 6 representing "strongly agree". One negatively worded item was reverse-coded so that a higher score was reflective of higher self-concept. Both the math and English self-concept scales had high reliability (math: $\alpha=.91$ and English: $\alpha=.94$ ).

Achievement goals. To measure students' achievement goals in math and English, we used the School Motivation Questionnaire (Marsh, Craven, Hinkley, \& Debus, 2003). There were two reasons for adopting this scale: firstly, this scale was shown to be reliable, valid, and invariant over time. Secondly, we considered the caution that is repeatedly mentioned by achievement goal researchers that the construct validity of instruments needs to be appropriate for the participants from the cultural groups to be studied (e.g., King et al., 2012). As Marsh et al. (2003) had validated the scale with Australian students, the instrument was deemed to be appropriate for our sample.

Mastery goal was measured using the intrinsic orientation scale (reflective of a mastery goal orientation), which consisted of six items on a 6-point scale with 1 representing "strongly disagree" and 6 indicating "strongly agree". Performance goal was measured using the competition orientation scale (reflective of a performance goal orientation), which also contained six items on a 6-point scale. The original items were for general schooling, so we made changes to reflect math and English respectively. The scales all showed high reliability (math mastery: .94, math performance: .96, English mastery: .94, and English performance: .92).

Math and English achievement scores. We used the 40 mathematics items of the Wide Ranging Achievement Test 4 (WRAT 4: Wilkinson \& Robertson, 2006), which measures mathematical computational skills. We used 42 spelling items and 41 sentence comprehension items 
from WRAT 4 to measure students' English achievement. The WRAT 4 has been used widely to gauge academic achievements and the tests have been reported to be reliable and valid (Wilkinson \& Robertson, 2006). A correctly answer scored one point, thus the highest maximum scores were 40 and 83 for math and English achievement tests respectively.

\section{Data Collection}

The data collection strictly followed the requirements prescribed by the university ethics committee. The consent from the participants and their parents' to participation on voluntary basis was obtained. Every effort was made to ensure the anonymity of the participants. Students completed the questionnaires before completing the math and English achievement tests.

\section{Statistical Analysis}

As all the scales used in the study are well-established, we started with our analysis by checking the Cronbach's alpha reliability of scales. Then confirmatory factor analysis (CFA) of a model was conducted with 2 self-concept scales, 4 achievement goal scales, and 2 achievement scores. Because the achievement scores were single item indicators, the measurement error of scores were fixed to $0 S D$ (equivalent to a perfect reliability estimate).

The CFAs were conducted using Mplus software version 7. Following Jöreskog and Sörbom (2005), to evaluate the CFA models, we considered three fit statistics as primary indicators of model fit - the Tucker-Lewis Index (TLI, Tucker \& Lewis, 1973), the Comparative Fit Index (CFI, Bentler, 1990), and the root mean square error of approximation (RMSEA, Browne \& Cudeck, 1993).

According to Bentler (1990), the values of TLI and CFI higher than .90 are generally considered an acceptable fit to the data. For the value of RMSEA, Browne and Cudeck (1993) suggest that RMSEA values below .06 are indicative a good fit.

Support for the CFA model also requires: (a) acceptable reliability for each scale (i.e., $\alpha=.70$ or above), (b) acceptable factor loadings for the items loading on the respective scales (i.e., factor loadings above .30), and (c) appropriate correlations among the latent factors to ensure that they 
would be distinguishable from each other ( $r$ s below .90). When the CFA model was established, we then conducted a series of tests to examine whether the model was factorial invariant by gender and cultural backgrounds. Evidence of invariance would enable us to compare gender and cultural groups using a MIMIC approach to structural equation modeling (SEM). In the current study, the MIMIC model examined the effects of three discrete grouping variables (a) gender (1=male, $2=$ female), (b) culture (1=Chinese, $2=$ Anglo), and (3) gender and cultural backgrounds interaction (i.e., gender $\mathrm{x}$ culture) on the 8 variables established in CFA.

\section{Results}

\section{Results of Reliability and CFA}

Each a priori scale was reliable ( $\alpha$ above .90). The CFA model (model 1), which included 6 factors and math and English achievement scores, fitted the data: $\chi^{2}(639)=4362.03$, TLI=.95, $\mathrm{CFI}=.95$, RMSEA $=.05$. All the factor loadings were above .64 , and the factor correlations were all below .7, supporting the CFA model.

\section{Results of Factorial Invariance across Groups}

Invariance across gender groups. The baseline model (model 2A) wherein the parameters were allowed to be freely estimated resulted in a good fit $\left(\chi^{2}(1278)=5274.89\right.$, TLI $=.95$, CFI $=.94$, RMSEA=.05). Model 2B, which imposed that all the factor loadings were equal across males and females, produced similar fit $\left(\chi^{2}(1308)=5328.58, T L I=.95, C F I=.94\right.$, RMSEA $\left.=.05\right)$, even though TLI was slightly reduced. Likewise, when the invariance constraints were imposed on both factor loadings and factor variances across groups in model 3C, a good fit was also attained $\left(\chi^{2}(1338)=5485.94, \mathrm{TLI}=.95, \mathrm{CFI}=.95, \mathrm{RMSEA}=.05\right)$. According to Cheung and Rensvold (2002), the negligible drops of our CFI in model 2B supported the factorial invariance by gender.

Invariance across cultural groups. The baseline model (model 3A) yielded a reasonable fit $\left(\chi^{2}(1278)=5164.64, \mathrm{TLI}=.95, \mathrm{CFI}=.95, \mathrm{RMSEA}=.05\right)$. Model 4B with factor loadings equal across groups also had a good fit $\left(\chi^{2}(1308)=5224.74\right.$, TLI=.95, CFI=.95, RMSEA=.05). Model 3C which 
specified invariance on both the factor loadings and factor variances had a comparable fit to model 4B $\left(\chi^{2}(1338)=5379.98, T L I=.95, \mathrm{CFI}=.95, \mathrm{RMSEA}=.05\right)$. These fit statistics provided us with a strong basis for group comparisons.

\section{MIMIC Model}

The MIMIC model displayed a good fit to the data, $\chi^{2}(729)=4581.70$, TLI=.95, CFI=.95, RMSEA=.05). The factor correlations of model 4 are displayed in Table 1. The factor loadings and paths are presented in Table 2.The correlations from Table 1 showed us that mastery goal $(r=.46$, $p<.01)$ and performance goals $(r=.70, p<.01)$ in the two subjects were strongly related to each other than self-concepts in the two subjects $(r=.11, p<.01)$. These results suggest that self-concepts are more domain specific than achievement goals.

\section{Table 1.Factor correlations of model 4}

\begin{tabular}{|c|c|c|c|c|c|c|c|c|}
\hline Variables & 1 & 2 & 3 & 4 & 5 & 6 & 7 & 8 \\
\hline 1 Math self-concept & --- & & & & & & & \\
\hline 2 Math mastery & $.57 * *$ & --- & & & & & & \\
\hline 3 Math performance & $.48 * *$ & $.39 * *$ & --- & & & & & \\
\hline 4 English self-concept & $.13^{* *}$ & $.09 * *$ & $.10 * *$ & --- & & & & \\
\hline 5 English mastery & $.09 * *$ & $.46^{* *}$ & $.16^{* *}$ & $.56 * *$ & --- & & & \\
\hline 6 English performance & $.21 * *$ & $.17 * *$ & $.70 * *$ & $.41 * *$ & $.37 * *$ & --- & & \\
\hline 7 Math achievement & $.49 * *$ & $.20 * *$ & $.26 * *$ & -.03 & -.04 & $.11 * *$ & --- & \\
\hline 8 English achievement & $.17 * *$ & -.03 & .04 & $.18 * *$ & -.01 & $.04 *$ & $.59 * *$ & --- \\
\hline
\end{tabular}

Note: ${ }^{* *} p<.01 ; * p<.05$.

The relations between self-concept and achievement goals within one subject (from .37 to .48) were stronger than respective relations across the two subjects (from .10 to .21 ). The math and English achievement scores showed a positive and moderate correlation $(r=.59, p<.01)$. The correlations of achievement scores with the self-concept $(r=.49, p<.01)$ and achievement goals in math $(r=.20, p<.01$ with math mastery goal; $r=.26, p<.01$ with math performance goal) were higher than those in English. English scores and English self-concept $(r=.18, p<.01)$, English scores and English mastery goal ( $r=-.01, p=.65)$, and English scores and English performance goals $(r=.04$, $p<.05)$ showed relatively lower correlations. Within each subject, achievement scores had higher 
correlation with the self-concept in that subject than achievement goals in that subject. Across the two subjects, we found that math achievement scores only weakly correlated with English performance goal $(r=.11, p<.01)$, and that English achievement scores only weakly associated with math self-concept $(r=.17, p<.01)$. These results supported the notion of domain specificity and the specificity matching principle (Arens et al., 2011).

Effect of gender. From Table 2, we can see that the main effect of gender was only significant for math performance goal. Specifically, a significantly negative path was found from gender to math performance goal $(\beta=-.20, p<.05)$, suggesting that female students had lower ratings on their math performance goal. However, the path from gender to math achievement was not statistically significant $(\beta=.11, p=.21)$, indicating that female students in fact did not perform poorly in math compared to male students. These results were in line with the notion of gender role stereotype in motivation-related beliefs in the domain of math (Meece et al., 2006) but not necessarily in actual math performance (Klapp Lekjolm \& Cliffordson, 2009).

Table 2. Solution of Model 4

\begin{tabular}{|c|c|c|c|c|c|c|c|c|}
\hline Variable & $\begin{array}{l}\text { Math } \\
\text { SC }\end{array}$ & $\begin{array}{l}\text { Math } \\
\text { Mas }\end{array}$ & $\begin{array}{l}\text { Math } \\
\text { Per }\end{array}$ & $\begin{array}{l}\text { English } \\
\text { SC }\end{array}$ & $\begin{array}{l}\text { English } \\
\text { Mas }\end{array}$ & $\begin{array}{l}\text { English } \\
\text { Per }\end{array}$ & $\begin{array}{l}\text { Math } \\
\text { Ach }\end{array}$ & $\begin{array}{l}\text { English } \\
\text { Ach }\end{array}$ \\
\hline \multicolumn{9}{|l|}{ Factor loadings } \\
\hline item 1 & $.84 * *$ & $.81 * *$ & $.85 * *$ & $.83 * *$ & $.88 * *$ & $.84 * *$ & 1.00 & 1.00 \\
\hline item 2 & $.81 * *$ & $.88 * *$ & $.91 * *$ & $.84 * *$ & $.84 * *$ & $.89 * *$ & --- & --- \\
\hline item 3 & $.74 * *$ & $.87 * *$ & $.91 * *$ & $.78 * *$ & $.83 * *$ & $.92 * *$ & --- & --- \\
\hline item 4 & $.73 * *$ & $.87 * *$ & $.90 * *$ & $.65 * *$ & $.75 * *$ & $.90 * *$ & --- & --- \\
\hline item 5 & $.86^{* *}$ & $.86 * *$ & $.91 * *$ & $.85 * *$ & $.85 * *$ & $.87 * *$ & --- & --- \\
\hline item 6 & $.79 * *$ & $.84 * *$ & $.87 * *$ & $.81 * *$ & $.81 * *$ & $.72 * *$ & --- & --- \\
\hline \multicolumn{9}{|l|}{ Uniqueness } \\
\hline item 1 & $.30 * *$ & $.34 * *$ & $.28 * *$ & $.31 * *$ & $.23 * *$ & $.30 * *$ & 0.00 & 0.00 \\
\hline item 2 & $.35 * *$ & $.22 * *$ & $.18 * *$ & $.30 * *$ & $.30 * *$ & $.22 * *$ & --- & --- \\
\hline item 3 & $.45^{* *}$ & $.24 * *$ & $.17 * *$ & $.40 * *$ & $.32 * *$ & $.15^{* *}$ & --- & --- \\
\hline item 4 & $.47 * *$ & $.24 * *$ & $.19 * *$ & $.58 * *$ & $.44 * *$ & $.21 * *$ & --- & --- \\
\hline item 5 & $.26 * *$ & $.26 * *$ & $.18 * *$ & $.27 * *$ & $.28 * *$ & $.24 * *$ & --- & --- \\
\hline item 6 & $.38 * *$ & $.30 * *$ & $.24 * *$ & $.35 * *$ & $.34 * *$ & $.48 * *$ & --- & --- \\
\hline \multicolumn{9}{|l|}{ Paths } \\
\hline Gender & -.03 & -.17 & $-.20 *$ & .16 & -.15 & -.09 & .11 & .10 \\
\hline Culture & -.06 & $-.16^{*}$ & $-.21 * *$ & $.20 * *$ & $-.15^{*}$ & -.09 & $-.36 * *$ & $-.18 * *$ \\
\hline Interaction & -.17 & -.10 & .08 & -.05 & $.36 * *$ & .06 & -.18 & -.02 \\
\hline
\end{tabular}


Note: $* * p<.01 ; * p<.05 . \mathrm{SC}=$ self-concept scale, Mas=Mastery orientation scale; Per=Performance orientation scale; Ach=Achievement.

Effect of culture. The main effect of culture was found for six variables out of ten examined, and among these significant paths, almost all were negative except for English self-concept ( $\beta=.20$, $p<.01)$. The positive path from culture to English self-concept suggested that Anglo-background students had significantly higher English self-concept compared to Chinese-background students. This might be because English was the first or the only language spoken by Anglo-background students, and this might boost Anglo-background students' beliefs in their English ability. However, we found a significantly negative path from culture to English achievement, suggesting that in reality it was the Chinese-background students who performed better in the English test even though their self-ratings of ability was lower than the Anglo-background students. The other significant and negative paths from culture were on math mastery goal $(\beta=-.16, p<.05)$, math performance goal ( $\beta=-.21, p<.01)$, English mastery goal $(\beta=-.15, p<.05)$, and math achievement $(\beta=-.36, p<.01)$. The descriptive statistics are shown in Table 3.

Interaction effect. A statistically significant interaction effect between gender and culture was found only on English mastery goal $(\beta=.36, p<.01)$. From Table 3, we can see that female Anglobackground students had the highest English mastery goal $(M=4.15)$, followed by female Chinesebackground students $(M=3.88)$ and male Chinese-background students $(M=3.85)$. The male Anglobackground students had the lowest ratings on their English mastery goal $(M=3.77)$.

Table 3. Descriptive statistics of the variables by groups

\begin{tabular}{lllll}
\hline \multirow{2}{*}{ Variables } & \multicolumn{2}{c}{ Males $M(S D)$} & \multicolumn{2}{c}{ Females $M(S D)$} \\
\cline { 2 - 5 } & Chinese(248) & Anglo(853) & Chinese (210) & Anglo(1032) \\
\hline Math self-concept & $4.82(0.86)$ & $4.52(0.95)$ & $4.60(0.86)$ & $4.18(1.01)$ \\
\hline Math mastery & $4.30(1.28)$ & $3.92(1.27)$ & $3.99(1.27)$ & $3.74(1.27)$ \\
\hline Math performance & $4.52(1.21)$ & $3.94(1.27)$ & $4.32(1.23)$ & $3.76(1.28)$ \\
\hline English self-concept & $3.81(1.07)$ & $4.24(1.00)$ & $4.06(0.97)$ & $4.47(0.94)$ \\
\hline English mastery & $3.85(1.09)$ & $3.77(1.20)$ & $3.88(1.08)$ & $4.15(1.10)$ \\
\hline English performance & $4.03(1.17)$ & $3.89(1.15)$ & $3.93(1.04)$ & $3.82(1.16)$ \\
\hline Math achievement & $34.42(5.02)$ & $27.42(6.30)$ & $34.79(4.26)$ & $26.75(6.07)$ \\
\hline English achievement & $60.34(15.20)$ & $53.66(13.29)$ & $62.54(14.31)$ & $55.78(12.44)$ \\
\hline
\end{tabular}




\section{Discussion}

The present study investigated gender and cultural effects on Australian high school students' self-concepts, achievement goals, and academic achievements in math and English. We found that cultural background had more effects on these variables than gender or the interaction between the two.

\section{Gender Difference}

The MIMIC model showed that the only noteworthy gender difference was on math performance goal. The negative effect suggested that male students tended to set performance goals higher, such as being better than their peers, in math subjects more than their female counterparts, even though math performance was equivalent between male and female students. This result is consistent with the current literature on gender stereotype in different curriculum areas. Male students, in general, have been shown to have higher competence beliefs in math and science related subjects (Meece et al., 2006; Midgley et al., 2001). The result also aligns with previous findings that male students tend to overestimate, whereas female students tend to underestimate, their math ability (Klapp Lekholm \& Cliffordson, 2009). In educational practice, teachers may need to make some efforts in boosting female students' beliefs of their competence in math and science related subjects. Based on the known reciprocal effects between self-concept and achievement (Marsh \& Craven, 2006), students may further increase their academic performance in these subjects through interventions that focus on boosting their competence beliefs (Craven \& Yeung, 2015).

\section{Cultural Differences}

The majority of the significant paths generated from our MIMIC model were from cultural background, which reflected that cultural backgrounds indeed made a difference on students' academic self-concepts, the achievement goals they set, as well as their levels of academic performance. We found that even though Chinese students outperformed Anglo students on both math and English achievements, they did not perceive their competence in the two subjects as higher 
than as perceived by the Anglo students. That is, the Chinese students' actual performance and their respective self-concepts were not commensurate with each other.

Interestingly, the positive path from culture to English self-concept indicated that the Anglo students were more confident about their English competence, even though their performance was inferior to that of the Chinese students. For Anglo students, English is the main, and probably the only, language they use. For the Chinese students in our sample, they reported that they mainly used either Mandarin or Cantonese at home. They may perceive English as their second language, or a language for school and social activities to interact with their peers. These could be reasons for them to underestimate their English competence.

However, we also observed a similar pattern in the math subject, showing that relatively, Chinese students seemed to underestimate their competence whereas Anglo students overestimated their math competence. Even though the two groups of students did not differ in their math competence beliefs, Chinese students were superior to their Anglo peers in the math test. These results seem to suggest that language may not be the reason that explains the Chinese students' lower self-concept in English; culture may be more important and suitable to explain the differences in self-concepts in both the English and math subjects. Chinese students' lower levels of self-concepts may have been affected by the values and educational beliefs they have held from the Chinese culture. Chinese culture, values, and beliefs, heavily influenced by traditional thoughts and Confucianism, emphasizes strongly that the human's fulfilment needs to be nurtured through effort and diligence, rather than through their "innate ability" (Hau \& Salili, 1991; Yeung \& Yeung, 2008, Yeung et al., 2016). By identifying themselves as Chinese, the students from a Chinese cultural background are likely to hold such values and beliefs as part of their identity (Luo et al., 2014).

These cultural beliefs may also explain why Chinese-background students had higher performance goals (though not for English performance goal), because they believed that they should work harder and be competitive to be better in the school subjects. Apart from higher performance 
goals, we observed that Chinese students were higher in mastery goal in math. As far as English mastery goal is concerned, we found that while the Anglo female and Anglo male students had the highest and the lowest English mastery goal respectively, the Chinese female and male students were in the middle. This means that for English, a verbal related subject, gender stereotype tended to be strong among Anglo students. For the Chinese students, such gender stereotype was much weaker. As mentioned earlier, Chinese culture sees knowledge seeking as a way to fulfil the meaning of life, and therefore Chinese students tend to set knowledge acquiring as their long-term goal to keep them motivated to learn ( $\mathrm{Li}, 2002)$. This important belief may equally influence Chinese male and female students and offset some of the effects from gender stereotype.

The results from our study add an extra piece of information regarding cultural effects on students' psychological factors in academic learning. It is important to note that even though our students migrated to an Australian society where Western cultures are predominant, and even though the Chinese-background students attended the same schools as the Anglo-background students, Chinese heritage seemed to have enduring effects on the Chinese students' academic beliefs and motivation. Hence although these students are educated under the same educational system, the culture that the Chinese-background students have inherited from their family could have maintained the values and beliefs of their ancestors. However, whereas high levels of motivation may be a pleasing finding for the Chinese-background students, their relatively lower competence beliefs could be worrisome. Given the known mutually reinforcing effects between academic self-concept and achievement, the Chinese students' relatively lower self-concepts may reflect limitations in their potential of achieving optimal performance.

\section{Implications for Educating Chinese-heritage Students}

This study highlights the importance of culture on students' self-beliefs and motivation in a multilingual and multicultural society. It is important for educators and practitioners to pay attention to the characteristics of learners from diverse cultures under the same educational system. To better 
educate learners from a Chinese background, teachers should boost students' sense of competence. They may try to help students to evaluate their abilities more appropriately. As past research consistently suggests that self-concept of competence and achievement are reciprocal and mutually enhancing each other (Marsh \& Craven, 2006), with an improved self-concept, Chinese learners may reach better academic achievement. Our findings call for self-concept enhancement interventions for Chinese-background students to maximize their potential.

\section{Strengths and Limitations}

The current study adds to the literature on Chinese-heritage learners' self-beliefs and motivation in a Western context. It explicates gender and culture patterns between Chinese- and Anglo-background learners within the same educational system, so that the similarities and differences observed could be attributed to culture rather than the educational system per se. Despite the interesting findings and the strength of the MIMIC approach, the study did have some limitations, which may be addressed in future research. As our sample included only high school students, we could not generalize the findings to Chinese learners of other age spans. It would be interesting to examine these variables among primary and secondary school students to see if Chinese- and Anglobackground learners at different educational levels differ. This way, we may obtain useful information about whether culture has profound effects from an early age and continuesthrough maturity.

Furthermore, our research was limited to an Australian schooling context. As Chinese-heritage learners spread over the world, both in Asian countries, such as in Singapore, Malaysia, and Indonesia, and in North American including the USA and Canada, it would be interesting to compare the self-concept and achievement goals of Chinese-heritage learners from Eastern and Western countries to reflect nuanced influences by culture.

\section{Conclusion}


The current study sought to compare two important academic psychological constructs - selfconcept and achievement goals, and academic achievement in math and English among 461 Chinesebackground and 1901 Anglo-background high school students in Australia using a MIMIC approach to SEM. For these high school students, gender did not have much significant effect whereas culture was an important factor, which exerted influences not only on their academic performance, but also on self-concept and motivation. In general, Chinese students outperformed their Anglo peers in the two subjects, and were more motivated to learn in both subjects, but had a lower sense of competence, especially in English. They tended to underestimate their academic competence. In their teaching practice with students from a Chinese background, teachers need to understand the Chinese culture and pay attention to the influence of culture on the students. For educating Chinese students, teachers may need to keep in mind the importance of boosting students' self-concept and beliefs in their competence.

\section{References}

Arens, A.K., Yeung, A.S., Craven, R.G., \& Hasselhorn, M. (2011). The twofold multidimensionality of academic self-concept: Domain specificity and separation between competence and affect components. Journal of Educational Psychology, 103, 970-981.

Bentler, P.M. (1990). Comparative fit indexes in structural models. Psychological Bulletin, 107, 238246.

Browne, M.W., \& Cudeck, R. (1993). Alternative ways of assessing model fit. In K.A. Bollen, \& J.S. Long (Eds.), Testing structural equation models (pp. 136-162). Beverly Hills, CA: Sage.

Cheung, G.W., \& Rensvold, R.B. (2002).Evaluating goodness-of-fit indexes for testing measurement invariance. Structural Equation Modeling, 9(2), 233-255.

Chiu, M.M., \& Klassen, R.M. (2010). Relations of mathematics self-concept and its calibration with mathematics achievement: Cultural differences among fifteen year olds in 34 countries.

Learning and motivation, 20, 2-17. 
Craven, R.G., Yeung, A.S. (2015). Motivation in Australian Aboriginal populations. In J. D. Wright (Ed.), International encyclopedia of the social \& behavioral sciences, 2nd ed. Vol. 15 (pp. 899-906). Oxford: Elsevier.

Dai, D.Y. (2001).A comparison of gender differences in academic self-concept and motivation between high-ability and average Chinese adolescents. Journal of Secondary Gifted Education, $13,22-32$.

Daniels, L.M., Haynes, T.L., Stupnisky, R.H., Perry, R.P., Newall, N.E., \& Pekrun, R. (2008). Individual differences in achievement goals: A longitudinal study of cognitive, emotional, and achievement outcomes. Contemporary Educational Psychology, 33, 584-608.

Dekker, S., \& Fischer, R. (2008). Cultural differences in academic motivation goals: A meta-analysis across 13 societies. The Journal of Educational Research, 102, 99-110.

Elliot, A.J. (2005). A conceptual history of the achievement goal construct. In A. J. Elliot, \& C. S. Dweck (Eds.), Handbook of competence and motivation (pp. 52-72). New York: Guilford Press.

Hau, K.T., \& Salili, F. (1991). Structure and semantic differential placement of specific cases: Academic causal attributions by Chinese students in Hong Kong. International Journal of Psychology, 26, 175-193.

Hulleman, C.S., Schrager, S.M., Bodmann, S.M., \& Harackiewicz, J.M. (2010). A meta-analytic review of achievement goal measures: Different labels for the same constructs or different constructs with similar labels. Psychological Bulletin, 136, 422-449.

Jöreskog, K.G., \& Sörbom, D. (2005).LISREL 8.72: Structural equation modelling with SIMPLIS command language. Chicago, IL: Scientific Software International.

King, R.B., Ganotice, F.A., \&Watkins, D.A. (2012). Cross-cultural validation of the Inventory of School Motivation (ISM) in the Asian setting: Hong Kong and the Philippines. Child Indicators Research, 5, 135-153. 
Klapp Lekholm, A., \& Cliffordson, C. (2009).Effects of student characteristics on grades in compulsory school. Educational Research and Evaluation, 15, 1-23.

Kurtz-Costes, B., Rowley, S., Harris-Britt, A., \& Woods, T.A. (2008).Gender stereotypes about mathematics and science and self-perceptions of ability in late childhood and early adolescence. Merrill-Palmer Quarterly, 54, 386-409.

Lai, F. (2010). Are boys left behind? The evolution of the gender achievement gap in Beijing's middle schools. Economics of Education Review, 29, 383-399.

Li, J. (2002). Models of learning in different cultures. In J. Bempechat \& J. G. Elliott (Eds.), New directions in child and adolescent development, no. 96: Achievement motivation in culture and context: Understanding children's learning experiences. San Francisco, CA: Jossey-Bass.

Luo, W., Hogan, D.J., Yeung, A.S., Sheng, Y.Z., \& Aye, K.M. (2014). Attributional beliefs of Singapore students: Relations to self-construal, competence and achievement goals. Educational Psychology, 34(2), 154-170.

Magson, N.R., Craven, R.G., Nelson, G.F., Yeung, A.S., Bodkin-Andrews, G.H., \& McInerney, D.M. (2014). Motivation matters: Profiling Indigenous and non-Indigenous students' motivational goals. The Australian Journal of Indigenous Education, 43(2), 1-17.

Mak, A.S. \& Chan, H. (1995).Families and Cultural Diversity in Australia. Retrieved on March $20^{\text {th }}$, 2016, from https://aifs.gov.au/publications/families-and-cultural-diversity-australia/4-chinesefamily-values-australia

Marsh, H.W. (1990). The structure of academic self-concept: The Marsh/Shavelson model. Journal of Educational Psychology, 82, 623-636.

Marsh, H.W., \& Craven, R.G. (2006). Reciprocal effects of self-concept and performance from a multidimensional perspective: Beyond seductive pleasure and unidimensional perspective. Perspectives on Psychological Science, 1, 133-163. 
Marsh, H.W., Craven, R.G., Hinkley, J.W., \& Debus, R.L. (2003). Evaluation of the Big-Two-Factor Theory of academic motivation orientations: An evaluation of jingle-jangle fallacies.

Multivariate Behavioral Research, 38,189-224.

Meece, J.L., Glienke, B.B., \& Burg, S. (2006). Gender and motivation. Journal of School Psychology, 44, 351-373.

Metallidou, P., \& Vlachou, A. (2007).Motivational beliefs, cognitive engagement, and achievement in language and mathematics in elementary school children. International Journal of Psychology, 42, 2-15.

Midgley, C., Kaplan, A., \& Middleton, M. (2001). Performance-approach goals: Good for what, for whom, under what circumstances, and at what cost? Journal of Educational Psychology, 93, $77-86$.

Möller, J., Retelsdorf, J., Köller, O., \& Marsh, H.W. (2011). The Reciprocal Internal/External Frame of Reference Model: An integration of models of relations between academic achievement and self-concept. American Educational Research Journal, 48, 1316-1346.

Nachtigall C, Kroehne U, Funke F, \& Steyer R. (2003). (Why) should we use SEM? Pros and cons of structural equation modeling. Method Psychology Research Online, 8, 1-22.

Pajares, F., \& Schunk, D.H. (2002). Self and self-belief in psychology and education: A historical perspective. In J. Aronson (Ed.), Improving academic achievement: Impact of psychological factors on education (pp. 3-21). San Diego, CA: Academic Press.

Paulick, I., Watermann, R., \& Nückles, M. (2013). Achievement goals and school achievement: The transition to different school tracks in secondary school. Contemporary Educational Psychology, 38, 75-86.

Pintrich, P.R. (2000). An achievement goal theory perspective on issues in motivation terminology, theory, and research. Contemporary Educational Psychology, 25, 92-104. 
Pinxten, M., Marsh, H.W., De Fraine, B., Van Den Noortgate, W., \& Van Damme, J. (2014).

Enjoying mathematics or feeling competent in mathematics? Reciprocal effects on mathematics achievement and perceived math effort expenditure. British Journal of Educational Psychology, 84, 152-174.

Seifert, T.L. (2004). Understanding student motivation.Educational Research, 46, 137-149.

Senko, C., Hulleman, C.S., \& Harackiewicz, J.M. (2011). Achievement goal theory at the crossroads: Old controversies, current challenges, and new directions. Educational Psychologist, 46, 2647.

Shavelson, R.J., Hubner, J.J., \& Stanton, G.C. (1976). Self-concept: Validation of construct interpretations. Review of Educational Research, 46, 407-441.

Swann, W.B., Jr., Chang-Schneider, C., \& Larsen McClarty, K. (2007).Do people's self-views matter? Self-concept and self-esteem in everyday life. American Psychologist, 62, 84-94.

Trautwein, U., \& Lüdtke, O. (2009).Predicting homework motivation and homework effort in six school subjects: The role of person and family characteristics, classroom factors, and school track. Learning and Instruction, 19, 243-258.

Tucker, L.R., \& Lewis, C. (1973). A reliability coefficient for maximum likelihood factor analysis. Psychometrika, 38, 1-10.

Urdan, T., \& Mestas, M. (2006).The goals behind performance goals. Journal of Educational Psychology, 98, 354-365.

Usher, E.L., \& Pajares, F. (2008). Self-efficacy for self-regulated learning. A validation study. Educational and Psychological Measurement, 68, 443-463.

Wilkinson, G.S., \& Robertson, G.J. (2006). WRAT4: Wide Range Achievement Test [Standardised Achievement Test]. Lutz, FL: Psychological Assessment Resources. 
Wolters, C.A. (2004). Advancing achievement goal theory: using goal structures and goal orientations to predict students' motivation, cognition, and achievement. Journal of Educational Psychology, 96, 236-250.

Worrell, F.C., Watkins, M.W., \& Hall, T.E. (2008). Reliability and validity of self-concept scores in secondary school students in Trinidad and Tobago. School Psychology International, 29, 466480.

Yeung, A.S. (2011). Student self-concept and effort: Gender and grade differences. Educational Psychology, 31, 749-772.

Yeung, A.S., Craven, R.G., \& Kaur, G. (2012). Gender differences in achievement motivation: Grade and cultural considerations. In S. McGeown (Ed.), Psychology of gender differences (pp. 59-79). New York: Nova Science Publishers.

Yeung, A.S., Han, F., \& Lee, F.L.M. (2016).Development of Chinese students' ability and effort beliefs influencing achievement. In King, R. B., \& A. B. I. Bernardo (Eds.), The psychology of Asian learners: A festschrift in honor of David Watkins (pp. 319-336). Singapore: Springer.

Yeung, A.S., \& Yeung, A. (2008). Ability vs. effort: Perceptions of students from the east and from the west. In O. S. Tan, D. M. McInerney, A. D. Liem, \& A. G. Tan (Eds.), Research on multicultural education and international perspectives. Vol. 7: What the west can learn from the east: Asian perspectives on the psychology of learning and motivation (pp. 77-99).

Greenwich, CT: Information Age. 